\title{
The role of social capital and community belongingness for exercise adherence: An exploratory study of the CrossFit gym model
}

\begin{abstract}
This is the first study to measure the 'sense of community' reportedly offered by the CrossFit gym model. A cross-sectional study adapted Social Capital and General Belongingness scales to compare perceptions of a CrossFit gym and a traditional gym. CrossFit gym members reported significantly higher levels of social capital (both bridging and bonding) and community belongingness compared with traditional gym members. However, regression analysis showed neither social capital, community belongingness, nor gym type were independent predictors of gym attendance. Exercise and health professionals may benefit from evaluating further the 'sense of community' offered by gym-based exercise programmes.
\end{abstract}

\section{Keywords}

Community health psychology, social capital, exercise behaviour, physical activity, social support.

\section{Introduction}

The long-term health benefits of exercise include reduced mortality rates from chronic illness such as, hypertension (Kokkinos, 2012) and cancer (Friedenreich, 2016) improved movement function in conditions such as arthritis (Macera et al., 2003) and reduced incidence and better management of conditions such as cardiovascular disease and diabetes (Reiner et al., 2013; Warburton et al., 2006). Additionally, exercise has been found to help improve psychological factors such as stress, anxiety and depression (Asmundson et al., 2013; Josefsson et al., 2013; Warburton et al., 2006). The short term benefits of exercise are also recognised, for example, Maher et al. (2013) found that satisfaction with life was improved among a sample of 18-25 year olds on days that they participated in exercise when compared to days they had not exercised. 
This is the authors' post-print copy of the manuscript. The article is published online in the Journal of Health Psychology and is available at: $\underline{\text { http://hpq.sagepub.com/content/early/2016/08/22/1359105316664132.abstract }}$ DOI: 10.1177/1359105316664132

Despite the known benefits of exercise, the UK government has highlighted that the UK population is not active enough to achieve a status of good health (Public Health England, 2013). National guidelines for the recommended levels of exercise advise that adults aged between 16-64 years old should participate in at least 150 minutes of moderate-intensity aerobic exercise (e.g. fast walking or cycling) or 75 minutes of vigorous-intensity aerobic exercise (e.g. running) each week. However, it has been reported that only $31 \%$ of the adult UK population met the NHS (2013) recommendations in 2014 (NatCen Social Research (2015).

The use of a gymnasium (gym) is one way in which people can increase their exercise levels. Traditional gym-based exercise is the primary method used to increase exercise levels through exercise referral schemes in the UK. The present study examines a novel gym environment, CrossFit, which is fast growing in popularity (Partridge et al., 2014). CrossFit began as a training regime originally founded by Greg Glassman in California, United States of America in the mid-nineties. Since then it has evolved into a trademarked company in the fitness industry with approximately 13,000 CrossFit gym affiliates worldwide. Recently, the UK fitness industry has seen a rise in the number of CrossFit Gyms (CFG) which currently stands at 501 (CrossFit Map, 2016). Distinct differences separate a CFG from a traditional gym (TG). CFGs are ordinarily located within industrial premises in industrial estates with an open plan floor space free from typical exercise equipment such as treadmills; instead, functional style equipment is used to facilitate exercise and the outdoor space is often utilised for exercising. The workouts consist of a variety of strength and conditioning exercises including: free weights, skipping, rowing and running. TGs are ordinarily found in purpose built buildings with modern interiors containing high tech electrically operated exercise apparatus often fitted with sockets for headphones and TV screens. Equipment in a TG includes rowing, cycling and treadmill exercise machines alongside a range of weight based machines and free weights.

Whilst both types of gym offer a way to increase exercise, some short fallings of gym based exercise have been recognised. For example, drop out from gym-based exercise programs has been shown to be high. 
This is the authors' post-print copy of the manuscript. The article is published online in the Journal of Health Psychology and is available at: $\underline{\text { http://hpq.sagepub.com/content/early/2016/08/22/1359105316664132.abstract }}$ DOI: 10.1177/1359105316664132

Matsumoto and Tekenaka (2004) found that $50 \%$ of people joining a gym fitness program will drop out after six months, and Dishman et al. (1985) reported a 20-50\% withdrawal of exercise programs in the first five to six months. Explorations into barriers for gym attendance have shown that personal barriers, such as lack of self-efficacy, low body image and poor time control, as well as contextual barriers have a profound influence on poor exercise adherence (Biddle et al., 2015). For example, the gym environment can be perceived as intimidating and not offering many opportunities for social interaction (Williams et al., 2007). Interventions to improve exercise adherence have often focused on influencing individual motivations, using theoretical models such as Self-Determination Theory (Deci and Ryan, 2002). Selfefficacy had been identified as a key factor for predicting (Flora et al., 2015) and improving exercise adherence (Buckley, 2014; McAuley and Blissmer, 2000), with studies demonstrating the positive impact of social support on self-efficacy (Resnick et al., 2002) and ultimately on levels of exercise adherence (Cooper et al., 2015). Nevertheless, to the researchers' knowledge no research has considered how the contextual environment and ethos of the gym itself may encourage social support. Exploring different types of gym models may give some insight into how social support could be facilitated and ultimately how this might impact on exercise adherence. Perhaps, instilling a sense of community or belongingness in a gym setting may influence participation and adherence to exercise.

The present study explores a unique contextual factor of a CFG, the social environment, by comparison to a TG. There are observable differences in the management of CFGs which may affect the social environment; two examples will be considered, the process of induction of new members and the group exercise program. New CFG members start at the same scheduled opportunity which occurs once per month, they spend six sessions together on a group induction; this gives opportunity to form social relationships. During this phase members are called 'on-rampers' which may give new members a social identity as suggested by Tajfel and Turner's (1986) theory. Additionally, this process may enhance a sense of belonging as suggested by Walton et al. (2012). Another way in which a CFG seeks to enhance the social environment is through the emphasis on group exercising, which has been found to have a positive effect on exercise adherence (Spink and Carron, 1992). Although members are given the 
This is the authors' post-print copy of the manuscript. The article is published online in the Journal of Health Psychology and is available at: $\underline{\text { http://hpq.sagepub.com/content/early/2016/08/22/1359105316664132.abstract }}$ DOI: $10.1177 / 1359105316664132$

flexibility of exercising alone, the programming of a single workout of the day (WOD) encourages members to exercise together during specified times slots throughout the day. Lee and Robins (1998) stated that an environment exhibiting community and promoting increased social interaction, where members have the opportunity to identify with other members, has the ability to strengthen a community environment. CrossFit appears to be grounded in an ethos of community building which may be expected to enable high levels of bridging and bonding social capital. Research surrounding social environments yields interesting findings which can be examined in relation to exercise adherence within gyms. Social support has been shown to be linked to greater self-efficacy and confidence (Molloy et al., 2010) which in turn can lead to increased participation in exercise. Group exercise programs offer greater opportunities to increase social support and create a social community in comparison to individual exercise. Markman (2012) noted that being surrounded by people who share the same goals results in a mutual interest of each other's progress. Social groups, such as belonging to an exercise group or gym, are thought to have the capacity to provide people with a sense of meaning, purpose and affiliation (Haslam et al., 2009) which can lead to positive psychological consequences, such as an increased sense of self-worth (Walton et al., 2012). In addition, when people feel like they belong to a group, they are more likely to participate in adaptive health behaviours (Dowd et al., 2014) and define their sense of self in terms of the groups they associate with as supported by social identity theory (Tajfel and Turner 1986). If people identify with an exercise group then they are more likely to place greater value on that behaviour (Burns et al., 2012). This relationship has also been found to be dynamic. Laverie (1998) discovered that people's decision to join an aerobics class was affected by the perceived social identity that would come as a result of joining, if positive social comparisons were made, they would be more inclined to attend.

There is currently no research to substantiate the presence of high social capital and community belongingness within a CFG. Internet searches yield a plethora of information which suggests that social support and a community ethos is high within a CFG but it is important to note that the concepts noted are anecdotal and not grounded in empirical research. This will be the first study to explore whether there are higher levels of social capital and community belongingness in CFG members compared with a group of 
TG members. It is hypothesised that higher levels of social capital and community belongingness will be exhibited by members of a CFG compared to members of a TG. It is also hypothesised that higher levels of social capital and community belongingness are associated with more frequent gym attendance, thus gym attendance will be greater among CFG members when compared to TG members.

\section{Methods}

\section{Participants}

An opportunity sample of one hundred gym members aged between 18 and 69 years were recruited from two different gym types; a CFG ( $n=50,27$ males and 23 females) and a TG $(n=50,25$ males and 25 females). The CFG and the TG were located within 0.5 miles of one another and therefore capture the same socio-demographic area in Cardiff, Wales, UK. Both gyms were equally accessible with similar opening hours and membership prices. The TG was embedded within a fitness centre, which incorporated additional swimming, tennis and cafe facilities as well as a crèche and nursery for childcare. Only members attending the fitness centre for the sole purpose of using the gym were approached to take part in the study. Members under the age of 18 years old were excluded. All of CFG members approached to take part in the study were recruited, however there was a $24 \%$ refusal rate for the TG sample.

\section{Procedure and design}

The study employed a cross-sectional design. A self-report questionnaire was used to collect data about social capital, community belongingness and gym attendance, as well as demographic characteristics, in order to make comparisons between the CFG and TG participants. The questionnaire was piloted on a small opportunity sample to test feasibility, face validity and reliability of the adapted scales. Minor amendments were made based on feedback. 
Recruitment of participants at the two gyms was undertaken using the same standardised format in both locations. Specifically, a suitable area was designated by the gym managers where the researcher could stand and approach potential participants. When approaching participants, the researcher explained what the study involved and the expected time it would take to complete, participants were given an information sheet to consider the research further and then invited to complete the questionnaire. The researcher was available at all times to answer any questions. When finished, participants were thanked for their time. The study was approved by the XXX Ethics Panel.

\section{Measures}

Sample characteristics. Information was collected on participants' sex, age (categorised into six age brackets, 18-29, 30-39, 40-49, 50-59, 60-69, 70 and above), and how long the participant had been a member at the gym (less than six months, six months to one year, one year to two years and two plus years).

Gym related characteristics. The questionnaire captured how participants spent the majority of their time at the gym (categorised into individual/independent training sessions, group training sessions, or equal amounts of time spent doing individual/independent training sessions and group training sessions).

Social capital. The Internet Social Capital Scale (Williams, 2006) was adapted to measure social capital within a gym context. The original scale comprises 20 items and was developed to measure Putnam's (2000) bridging and bonding constructs. Participants answer each item on a five point Likert scale ranging from one (strongly disagree) to five (strongly agree). This scale exhibits high validity for both bridging (10 items) and bonding (10 items) as distinct concepts and dimensions of social capital (Williams, 2006). In general population samples, the scale has been shown to exhibit high internal reliability ( $\alpha=.87-.93$; Pinho and Soares, 2015). The present study included six items from both the 
bridging subscale and the bonding subscale. Items were included if they were an appropriate fit for the context of the present study and were adapted for use with gym samples (see Table 1). The scoring range for the bonding and bridging subscales was from 6 to 30 and for total social capital the combined range was from 12 to 60 . The internal reliability for the adapted scale was $\alpha=0.94 \alpha=0.92$ and $\alpha=0.90$ for the bridging, bonding and combined social capital scales, respectively.

Community belongingness. The General Belongingness Scale (GBS) (Malone, Pillow and Osman, 2012) was adapted to measure gym community belongingness within the CFG and TG. The GBS is a 12 item scale which measures feelings of general belongingness across multiple levels of relationships. This is the first time that the scale has been adapted for use in an exercise context. The scale reports high levels of reliability and validity (Malone, Pillow and Osman, 2012) and has been shown to have an internal consistency of $\alpha=.95$ (Cockshaw, Shochet and Obst, 2013). Previous exploratory and confirmatory factor analysis has revealed that the 12 items fall into a two factor structure, acceptance/inclusion and rejection/exclusion which enables participants to report a sense of belonging to the extent that they feel both included and excluded (Malone, Pillow and Osman, 2012). Responses are recorded on a five point Likert scale ranging from one (strongly agree) to five (strongly disagree). Eight items from the scale were included in this study, giving a score range from 8 to 40 (see Table 1 for examples). Items were included if they were judged to fit the context of the research. The internal reliability of the adapted GBS was $\alpha=0.92$.

Gym attendance. The questionnaire used one item to measure gym attendance, 'during a typical week, how many times do you attend the gym?' Responses to this question were categorised into one, two, three, four, five, six, seven and seven and above attendances per week. Gym attendance was measured as a proxy for exercise adherence. 
Table 1. Original and adapted questionnaire items to measure social capital and community belongingness.

\begin{tabular}{|c|c|}
\hline \multicolumn{2}{|l|}{ Internet Social Capital Scale (Williams, 2006) } \\
\hline Original Item & Adapted Item \\
\hline \multicolumn{2}{|l|}{ Bridging Subscale } \\
\hline $\begin{array}{l}\text { Interacting with people online/offline makes me } \\
\text { interested in things that happen outside of my town } \\
\text { Interacting with people online/offline makes me } \\
\text { want to try new things }\end{array}$ & $\begin{array}{l}\text { Interacting with people from the gym makes me } \\
\text { interested in things that happen outside of my gym } \\
\text { Interacting with people from my gym makes me } \\
\text { want to try new things }\end{array}$ \\
\hline \multicolumn{2}{|l|}{ Bonding Subscale } \\
\hline $\begin{array}{l}\text { There are several people online/offline I trust to } \\
\text { help solve my problems } \\
\text { There is someone online/offline I can turn to for } \\
\text { advice about making very important decisions }\end{array}$ & $\begin{array}{l}\text { There are several people from the gym I trust to } \\
\text { help solve my problems } \\
\text { There is someone from the gym I can turn to for } \\
\text { advice about making very important decisions }\end{array}$ \\
\hline \multicolumn{2}{|c|}{ The General Belongingness Scale (GBS) (Malone, Pillow and Osman, 2012) } \\
\hline Original Item & Adapted Item \\
\hline \multicolumn{2}{|l|}{ Acceptance/inclusion } \\
\hline $\begin{array}{l}\text { When I am with other people, I feel included } \\
\text { I have close bonds with family and friends }\end{array}$ & $\begin{array}{l}\text { When I am at the gym I feel included } \\
\text { I have close bonds with people at the gym }\end{array}$ \\
\hline \multicolumn{2}{|l|}{ Rejection/exclusion } \\
\hline $\begin{array}{l}\text { I feel like an outsider } \\
\text { I feel as if people do not care about me }\end{array}$ & $\begin{array}{l}\text { I feel like an outsider at my gym } \\
\text { I feel as if people do not care about me at my gym }\end{array}$ \\
\hline
\end{tabular}

\section{Data analyses}

Total scores were computed for social capital and the social capital subscales (bridging and bonding) and community belongingness. T-test analyses were used to explore the levels of social capital, community belongingness and gym attendance across the samples. Pearson's correlation analyses were used to explore associations between social capital, community belongingness and gym attendance. A linear 
This is the authors' post-print copy of the manuscript. The article is published online in the Journal of Health Psychology and is available at: $\underline{\text { http://hpq.sagepub.com/content/early/2016/08/22/1359105316664132.abstract }}$ DOI: $10.1177 / 1359105316664132$

regression model was conducted to examine associations between gym type, social capital, community belongingness and gym attendance. Levene's test was used to check the variance for all t-tests conducted. All effect sizes were calculated by hand using the formula $r=\sqrt{ } t 2 / t 2+d f$ as cited in Field (2009). Benchmarks for effect size are indicated by Field (2009) to be, $r=.1$ for a small effect accounting for one percent of the total variance, $r=.3$ for a medium effect and nine percent variance and $r=.5$ for a large effect accounting for $25 \%$ total variance.

Table 2. Sample characteristics

\begin{tabular}{|c|c|c|}
\hline & $\begin{array}{l}\text { CrossFit gym } \\
\text { members }(n=50)\end{array}$ & $\begin{array}{l}\text { Traditional gym } \\
\text { members }(n=50)\end{array}$ \\
\hline \multicolumn{3}{|l|}{ Sex } \\
\hline Male & 27 & 25 \\
\hline Female & 23 & 25 \\
\hline \multicolumn{3}{|l|}{ Age } \\
\hline $18-29$ years & 24 & 12 \\
\hline 30-39 years & 21 & 13 \\
\hline $40-49$ years & 4 & 15 \\
\hline 50 plus years & 1 & 10 \\
\hline \multicolumn{3}{|l|}{ Length of gym membership } \\
\hline$<$ six months & 4 & 2 \\
\hline Six months - one year & 10 & 5 \\
\hline One - Two years & 21 & 4 \\
\hline$>$ Two years & 15 & 39 \\
\hline \multicolumn{3}{|l|}{ Type of gym activity } \\
\hline $\begin{array}{l}\text { Individual or independent } \\
\text { activities }\end{array}$ & 0 & 28 \\
\hline Group activities & 33 & 13 \\
\hline $\begin{array}{l}\text { Mix of individual and group } \\
\text { activities }\end{array}$ & 17 & 9 \\
\hline
\end{tabular}




\section{Results}

\section{Sample characteristics}

The sample characteristics are presented in Table 2. As can be seen, a higher proportion of younger members were found in the CFG sample. Chi-square analysis showed a significant association between age and gym type $(X 2=19.614$, df $(3), \mathrm{p}<.001)$. Participants from the CFG included more new members (58\% had been a member for two years and under), than the TG sample participants (22\% had been a member for two years and under) of whom the majority had been a member from more than two years $(78 \%)$.

\section{Gym related characteristics}

Differences were identified in the way 'the majority of time was spent at the gym' between the CFG and TG samples. The CFG participants were more likely to engage in group training sessions than participants of the TG. Conversely participants from the TG were more likely to engage in individual/independent training sessions than participants from the CFG.

\section{Social capital and community belongingness}

Social capital was found to be significantly higher in the CFG sample $(M=51.6, S E=.755)$ than in the TG sample $(M=39.3, \mathrm{SE}=1.44), \mathrm{t}(74)=7.5, \mathrm{p}=.001, r=.65$. The $\mathrm{CFG}$ sample also showed significantly higher scores for both subscales of social capital; bridging $(\mathrm{M}=27.1, \mathrm{SE}=.340) \mathrm{t}(69)=7.52, \mathrm{p}=.001, r=$ .67 than the $\mathrm{TG}$ sample $(\mathrm{M}=21.1, \mathrm{SE}=.724)$; and bonding $(\mathrm{M}=24.4, \mathrm{SE}=.581) \mathrm{t}(87)=6.07, \mathrm{p}=.001, r=$ .54 , than in the TG sample $(\mathrm{M}=18.2, \mathrm{SE}=.842)$. Additionally, feelings of community belongingness were found to be significantly higher in the CFG sample $(M=37.0, S E=.519)$ than in the TG sample $(M=30.6$, $\mathrm{SE}=.837), \mathrm{t}(82)=6.51, \mathrm{p}=.001, r=.58$. All of the effect sizes for these findings were large $(\mathrm{r}>.5)$. These findings support the hypothesis that significantly higher levels of social capital and community belongingness would be exhibited by people who attend a CFG compared to people who attend a TG. As previously noted there were differences in the ages of participants across the two samples. Consequently, 
the data were examined to explore whether these age differences may account for the observed differences in social capital and general belongingness scores by gym type. Inferential statistical analysis (such as ANCOVA) was not appropriate as the age category variable was not independent of the gym type variable (Field, 2009). However, the pattern of data demonstrated that ratings for all social capital and general belongingness scores were higher for CFG members compared with TG members for each of the individual age categories, see examples in Figures 1 and 2.

[Insert Figure 1 and 2]

\section{Gym attendance}

There was no significant difference in gym attendance between gym types, members of the CFG sample attended the gym marginally more in a week $(\mathrm{M}=4.94, \mathrm{SE}=.21)$ than members of the TG sample $(\mathrm{M}=$ $4.58, \mathrm{SE}=.23), \mathrm{t}(98)=1.134, \mathrm{p}=.260$. The majority of all participants attended the gym four or five times per week.

A Pearson's correlation analysis was conducted to establish whether there were significant relationships between attendance and the measures of social capital and community belongingness. Results showed a significant positive correlation between social capital and attendance $(\mathrm{r}=.28, \mathrm{p}=.005)$, such that as social capital increases weekly gym attendance also increases. Secondly, a significant positive correlation between attendance and community belongingness was also observed $(r=.27, p=.007)$. To establish if there was an association with gym type, a linear regression was conducted. This showed that social capital, community belongingness and gym type accounted for six percent of the variance in gym attendance $\left(\mathrm{R}^{2}=.063\right)$. An analysis of variance (ANOVA) indicated that the regression model is significantly better at predicting gym attendance than the mean value of gym attendance $(\mathrm{F}=2,436$, $\mathrm{p}=.016)$. However, neither social capital $(\mathrm{b}=.22, \mathrm{p}>.05)$, community belongingness $(\mathrm{b}=.16, \mathrm{p}>0.05)$, or gym type $(b=.10, \mathrm{p}>.05)$ were found to be independent significant predictors of gym attendance. Therefore, despite support for the hypothesis that higher levels of social capital and community 
belongingness are related to higher gym attendance, the hypothesis that CFG members would have higher gym attendance than TG members was not supported.

\section{Discussion}

The present study is the first to compare social capital and community belongingness in relation to two gym types; a CrossFit gym and a traditional gym. As expected, based on the ethos of CrossFit, levels of group exercise were found to be higher within the CFG compared to the TG where individual exercise was most common. It was hypothesised that the group exercise model and process of group induction of new members in the CFG would be represented by higher levels of social capital and community belongingness within the CFG sample compared to the TG sample. The results supported these hypotheses with CFG members reporting significantly higher levels of social capital on both the bridging and bonding subscales of social capital as well as significantly higher levels of community belongingness. This finding suggests that the group exercise model and group induction process within the CFG may provide greater opportunity for diverse social networking (bridging) as well as opportunity for deeper friendship development (bonding) compared to the TG. It could therefore be argued that the group exercise model offered in the CFG may provide an environment more open to social interaction and feelings of social identity. It should also be acknowledged that it may also be true that individuals who are more open to social interaction are more attracted to the CrossFit gym model.

Based on existing research suggesting that a lack of social support is linked to drop out from exercise (Williams et al., 2007), in addition to evidence that belonging to a socially supportive group increases adaptive health behaviours (Dowd et al., 2014), it was predicted that members of the CFG would have higher attendance rates than members of the TG. However, a significant difference was not found in gym attendance between the two samples meaning that this hypothesis was unsupported. An explanation for this finding could be that previous research such as Williams et al. (2007) was conducted on sample of non-exercisers up taking exercise as a new behaviour change, whereas the participants in this study were 
already active gym members. In addition, Williams et al's participants experienced recognised comorbidities which could have influenced dropout rates.

Participants in the present study were asked to record how long they had been a member of their respective gyms. Results showed that a higher number of participants from the TG had memberships for more than two years whereas the CFG had a higher amount of newer members. Based on this finding it could be argued that the TG members had a longer time to engage in social capital and community building opportunities and yet TG members reported lower feelings of social capital and community belongingness than CFG members. Conversely, differing age distributions were apparent among the two samples, the TG participants were found to be older than the CFG participants. Lifespan research suggests that younger adults typically work harder at building social networks whilst older generations are more likely to narrow their social networks (Sigelman and Rider, 2012). Therefore, it could be suggested that the younger sample seen in the CFG are more open to social interactions than the older sample of the TG. The unbalanced age distribution of the CFG and TG sample highlights a limitation of the research. However, the pattern of data suggest the differences in social capital and belongingness scores exist even when comparing within each age category. Further investigation is needed to confirm whether age is a mediating factor in the relationship between gym type and levels of social capital and belongingness. The differences in age distribution may be a reflection of the type of exercise offered or the facilities available (e.g. a crèche is available at the TG). This study did not aim to explore the factors underlying the choice of gym or how this impacted on feelings of belongingness but simply aimed to observe whether differences in community belongingness exist. Exploring the reasons underlying the choice of gym would be a useful area for future study.

Positive correlations were observed between gym attendance and the measures of social capital and community belongingness. A linear regression was conducted to establish whether gym type along with social capital and community belongingness was a predictor of gym attendance. Only $6 \%$ of the variance in gym attendance was accounted for by social capital, community belongingness and gym type, 
indicating that $94 \%$ of the variation in gym attendance cannot be explained by these three factors and other variables are influencing gym attendance. The present research has considered belongingness as a key differentiator between the CFG and TG models but recognises that many other differences are present between the two models which may account for other variance in the prediction of gym attendance. Individual factors in motivation, and other personal barriers and facilitators may account for some of this variance (Biddle et al., 2015); unfortunately limitations in the sample size of this study prevented mediation analyses to explore the effect of motivation. There is also scope for future research exploring the novel gym environment of a CFG such as differences in the physical environment of the two gym types. For example, there are abundant mirrors present in TGs whereas CFGs do not usually contain mirrors; previous research suggests that exercising in front of mirrors can have a negative impact on feeling states in women (Martin-Ginis and Jung, 2003) and increased self-focus and higher body image concerns (Katula, McAuley, Mihalko and Bane, 1998).

This study was the first to empirically investigate differences in social capital and belongingness between different gym types. As an exploratory study with a cross-sectional design and a relatively small sample, the conclusions are limited to associations. Nevertheless, the higher levels of social capital and belongingness felt by CFG members suggest the potential for further research. Experimental research would help establish cause and effect relationships rather than associative relationships between social capital, community belongingness and gym attendance as seen in the present cross-sectional design. The CFG and TG participating in this research were in close proximity to each other and with similar membership fees suggesting that the socioeconomic catchment for participants was the same; however, a limitation of the study was that no socioeconomic data were collected from the participants. Another limitation of the study was that participants were recruited from only one example of a CFG and one TG, thus the generalisation of these findings to other CFGs and TGs is limited. Future research could recruit participants from a range of CFGs and TGs to see if the findings of the present research can be generalised to other examples of these gym types. 
This study is the first piece of research to provide support for the claim that the CrossFit gym model may offer a greater level of community ethos compared with a traditional gym. Specifically, members of a CrossFit gym had higher levels of social capital and feelings of community belongingness than members of a similar traditional gym. However, given the exploratory nature of this study further research is needed to investigate the impact of the social context of gym-based programmes on exercise adherence. For example, it would be useful to evaluate how a 'sense of community' might affect motivation or selfefficacy in gym members and the subsequent impact on exercise adherence. Given the high dropout rates for gym-based exercise programmes, the present study and future related research could be invaluable in efforts to support individuals to adhere to exercise in the long term.

\section{Acknowledgements}

The authors wish to thank the CrossFit gym manager and the traditional gym manager for allowing the research to be conducted on their premises, in addition to the gym members for agreeing to participate in the study. Health and Care Research Wales Workforce are also thanked for supporting the first author during the study. The input of the second author was undertaken with the support of The Centre for the Development and Evaluation of Complex Interventions for Public Health Improvement (DECIPHer), a UKCRC Public Health Research Centre of Excellence. Joint funding (MR/KO232331/1) from the British Heart Foundation, Cancer Research UK, Economic and Social Research Council, Medical Research Council, the Welsh Government and the Wellcome Trust, under the auspices of the UK Clinical Research Collaboration, is gratefully acknowledged.

\section{Funding}

This research received no specific grant from any funding agency in the public, commercial, or not-forprofit sectors. 
This is the authors' post-print copy of the manuscript. The article is published online in the Journal of Health Psychology and is available at: $\underline{\text { http://hpq.sagepub.com/content/early/2016/08/22/1359105316664132.abstract }}$ DOI: 10.1177/1359105316664132

\section{References}

Asmundson GJG, Fetzner MG, DeBoer LB, Powers MB, Otto MW and Smits JAJ (2013) Let's get physical: A contemporary review of the anxiolytic effects of exercise for anxiety and its disorders. Depression \& Anxiety 30(4) 362-373.

Biddle SJH, Mutrie N and Gorley T (2015) Psychology of Physical Activity: Determinants, Well-being and Interventions ( ${ }^{\text {rd }}$ Edition). London: Routledge.

Buckley J (2014) Exercise self-efficacy intervention in overweight and obese women. Journal of Health Psychology Epub ahead of print 21 August, 2014. DOI:10.1177/1359105314545096

Burns GN, Jasinski D, Dunn SC and Fletcher D (2012). Athlete identity and athlete satisfaction: The nonconformity of exclusivity. Personality and Individual Differences 52(3): 280-284.

Cockshaw, WD, Shochet IM and Obst PL (2013) General belongingness, workplace belongingness, and depressive symptoms. Journal of Community \& Applied Social Psychology, 23 (3): 240-25.

Cooper LB, Mentz RJ, Sun JL, Schulte PJ, Fleg JL, Cooper LS, Pina IL, Leifer ES, Kraus WE, Whellan DJ, Keteyjan SJ and O'Connor CM (2015) Psychosocial Factors, Exercise Adherence, and Outcomes in Heart Failure Patients: Insights From Heart Failure: A Controlled Trial Investigating Outcomes of Exercise Training (HF-ACTION). Circulation Heart Failure 8(6): 1044-1051.

Friedenreich CM, Wang Q, Neilson HK, Kopciuk KA, McGregor SE, Courneya KS. (2016) Physical Activity and Survival After Prostate Cancer. European Urology. 2016 Jan 7.

CrossFit. (2016) CrossFit Maps. Available at: http://map.crossfit.com/ (Accessed on 12 January 2016).

Deci E and Ryan R (Eds.) (2002) Handbook of Self-Determination Research. New York: University of Rochester Press.

Dishman RK, Sallis JF and Orenstein DR (1985) The determinants of physical activity and exercise. Public Health Reports 100(2): 158-171.

Dowd AJ, Schmader T, Sylvester BD, Jung ME, Zumbo BD, Martin LJ and Beauchamp MR (2014) Effects of social belonging and task framing on exercise cognitions and behaviour. Journal of Sport and Exercise Psychology 36(1): 80-92.

Field A (2009) Discovering Statistics using SPSS (3rd edition). London: SAGE Publications Limited.

Flora PK, Brawley L, Sessford JD, Cary, MA and Gyurcsik NC (2015) Predicting planned physical activity of individuals with arthritis: A self-regulatory perspective. Journal of Health Psychology. Epub ahead of print 12 May 2015. DOI: 10.1177/1359105315583370.

Haslam SA, Jetten J, Postmes T and Haslam C (2009) Social identity, health and wellbeing: An emerging agenda for applied psychology. Applied Psychology: An International Review 58(1): 1-23.

Josefsson T, Lindwall M and Archer T. Physical exercise intervention in depressive disorders: Metaanalysis and systematic review. Scandinavian Journal of Medicine \& Science in Sports 24(2): 259-272.

Katula, JA, McAuley E, Mihalko SL and Bane SM (1998) Mirror, mirror on the wall: Exercise environment influences on self-efficacy. Journal of Social Behaviour and Personality 13(2): 319-332. 
This is the authors' post-print copy of the manuscript. The article is published online in the Journal of Health Psychology and is available at: $\underline{\text { http://hpq.sagepub.com/content/early/2016/08/22/1359105316664132.abstract }}$ DOI: 10.1177/1359105316664132

Kokkinos, P (2012). Physical Activity, Health Benefits, and Mortality Risk. ISRN Cardiology. 2012: 718789. Epub http://doi.org/10.5402/2012/718789.

Laverie DA (1998) Motivations for ongoing participation in a fitness activity. Leisure Sciences 20(4): 277-302.

Lee RM and Robins SB (1998) The relationship between social connectedness and anxiety, self esteem and social identity. Journal of Counselling Psychology 45(3): 338-345.

McAuley E and Blissmer B (2000) Self-efficacy determinants and consequences of physical activity. Exercise and Sport Sciences Reviews 28(2): 85-88.

Macera CA, Hootman JM and Sniezek JE (2003) Major public health benefits of physical activity. Arthritis and Rheumatism 49(1): 122-128.

Maher JP, Doerksen SE, Elavsky S, Hyde A., Pincus AL, Ram N and Conroy DE (2013). A daily analysis of physical activity and satisfaction with life in emerging adults. Health Psychology 32(6): 647-656.

Malone GP, Pillow DR and Osman A (2012) The general belongingness scale (GBS): Assessing achieved belongingness. Personality and Individual Differences 52: 311-316.

Markman A (2012) It is motivating to belong to a group. Psychology Today. Available at http://www.psychologytoday.com/blog/ulterior-motives/201203/it-is-motivating-belong-group (Accessed on 21 January 2014).

Martin-Ginis KA, Jung ME and Gauvin L (2003) To see or not to see: Effects of exercising in mirrored environments on sedentary women's feeling states and self efficacy. Health Psychology 22(4): 354-361.

Matsumoto H and Tekenaka K (2004) Motivational profiles and stages of exercise behaviour change. International Journal of Sport and Health Sciences 2 :89-96.

Molloy GJ, Dixon D, Hamer M. and Sniehotta FF (2010) Social support and regular physical activity: Does planning mediate this link? British Journal of Health Psychology 15(4): 859-870.

NatCen Social Research (2015) Welsh Health Survey, 2013. [data collection]. UK Data Service. SN: 7632, http://dx.doi.org/10.5255/UKDA-SN-7632-1 (accessed 11 Jan 2015).

National Health Service Choices (2013) Physical Activity Guidelines for Adults. Available at: http://www.nhs.uk/Livewell/fitness/Pages/physical-activity-guidelines-for-adults.aspx (Accessed 30 May 2014).

Partridge JA, Knapp BA and Massengale BD (2014) An investigation of motivational variables in CrossFit facilities. The Journal of Strength and Conditioning Research 28(6): 1714-1721.

Pinho JC and Soares AM (2015) Response to advertising on online social networks: The role of social capital. International Journal of Consumer Studies 39: 239-248.

Public Health England (2013) Government consultations: Developing a national physical activity approach. Available at: https://www.gov.uk/government/consultations/development-of-a-nationalphysical-activity-approach (Accessed 30 May 2014).

Putnam RD (2000) Bowling alone: The collapse and revival of American community. New York: Simon $\&$ Schuster. 
Reiner M, Niermann C, Jekauc D and Woll A (2013) Long-term health benefits of physical activity - a systematic review of longitudinal studies. BMC Public Health 13: 813.

Resnick B, Orwig D, Magaziner J and Wynne C (2002) The effect of social support on exercise behavior in older adults. Clinical Nursing Research 11(1): 52-70.

Sigelman CK and Rider EA (2012) Life-span Human Development (Eight Edition). Stanford: Cengage Learning.

Spink KS. and Carron AV (1992) Group cohesion and adherence in exercise classes. Journal of Sport and Exercise Psychology 14(1): 78-86.

Tajfel H and Turner JC (1986) The social identity theory of intergroup behaviour. In S Worchel and WG Austin (Eds.), Psychology of Intergroup Relations (pp. 7-24). Chicago: Nelson-Hall.

Walton GM, Cohen GL, Cwir D and Spencer SJ. (2012) Mere belonging: The power of social connections. Journal of Personality and Social Psychology 102(3): 513-532.

Warburton DER, Nicol CW, Bredin SSD (2006) Health benefits of physical activity: The evidence. Canadian Medical Association Journal 174(6): 801-809.

Williams D (2006) On and off the 'net: Scales for social capital in an online era. Journal of ComputerMediated Communication 11(2): 593-628.

Williams NH, Hendry M, France B, Lewis R and Wilkinson C (2007) Effectiveness of exercise-referral schemes to promote physical activity in adults: A systematic review. British Journal of General Practice 57(545): 979-986. 
This is the authors' post-print copy of the manuscript. The article is published online in the Journal of Health Psychology and is available at: http://hpq.sagepub.com/content/early/2016/08/22/1359105316664132.abstract DOI: 10.1177/1359105316664132

Figure 1. Comparison of mean scores for total social capital by gym membership type for each age category

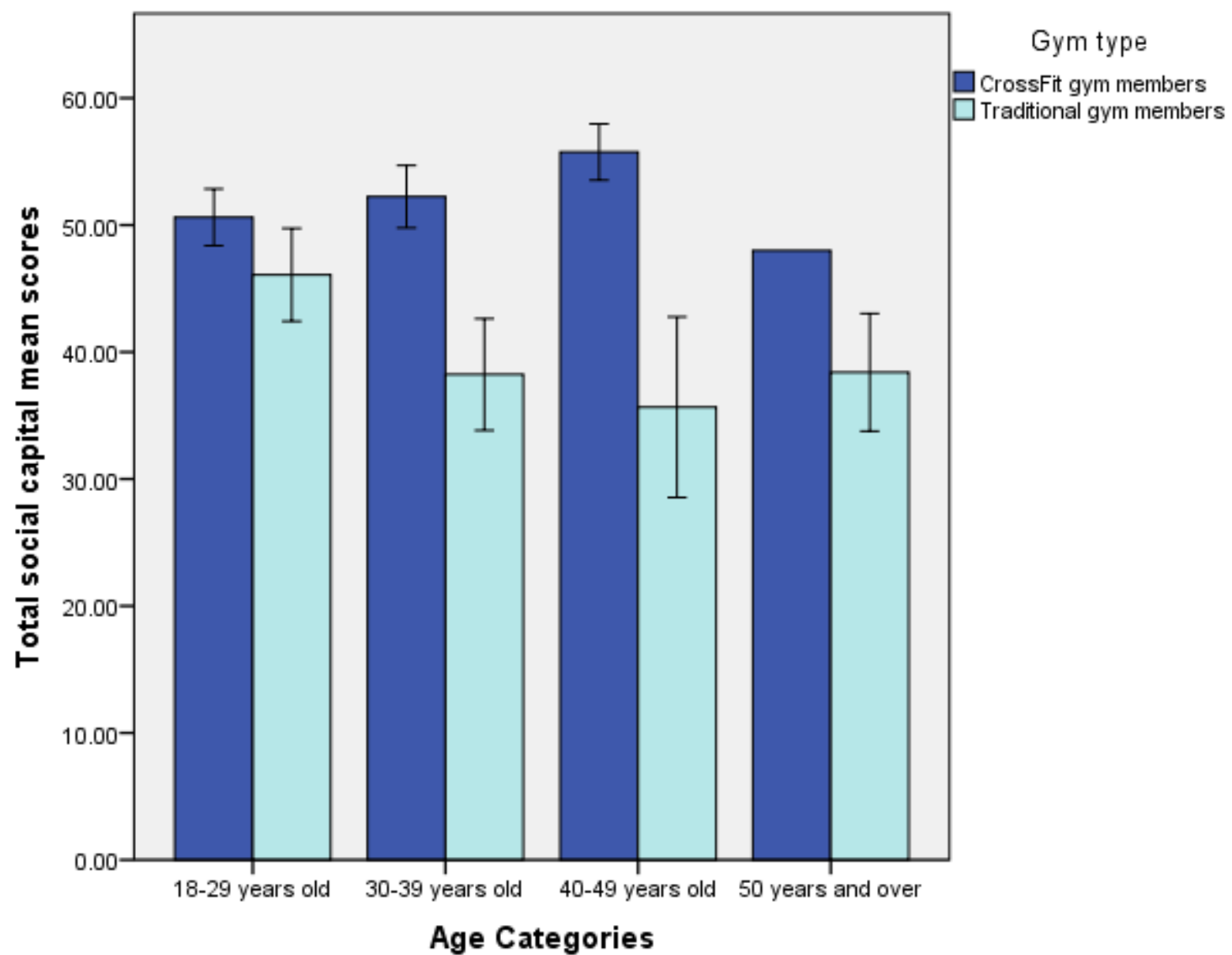

Error Bars: +/- 2 SE 
This is the authors' post-print copy of the manuscript. The article is published online in the Journal of Health Psychology and is available at: http://hpq.sagepub.com/content/early/2016/08/22/1359105316664132.abstract DOI: 10.1177/1359105316664132

Figure 2. Comparison of mean scores for general belongingness by gym membership type for each age category

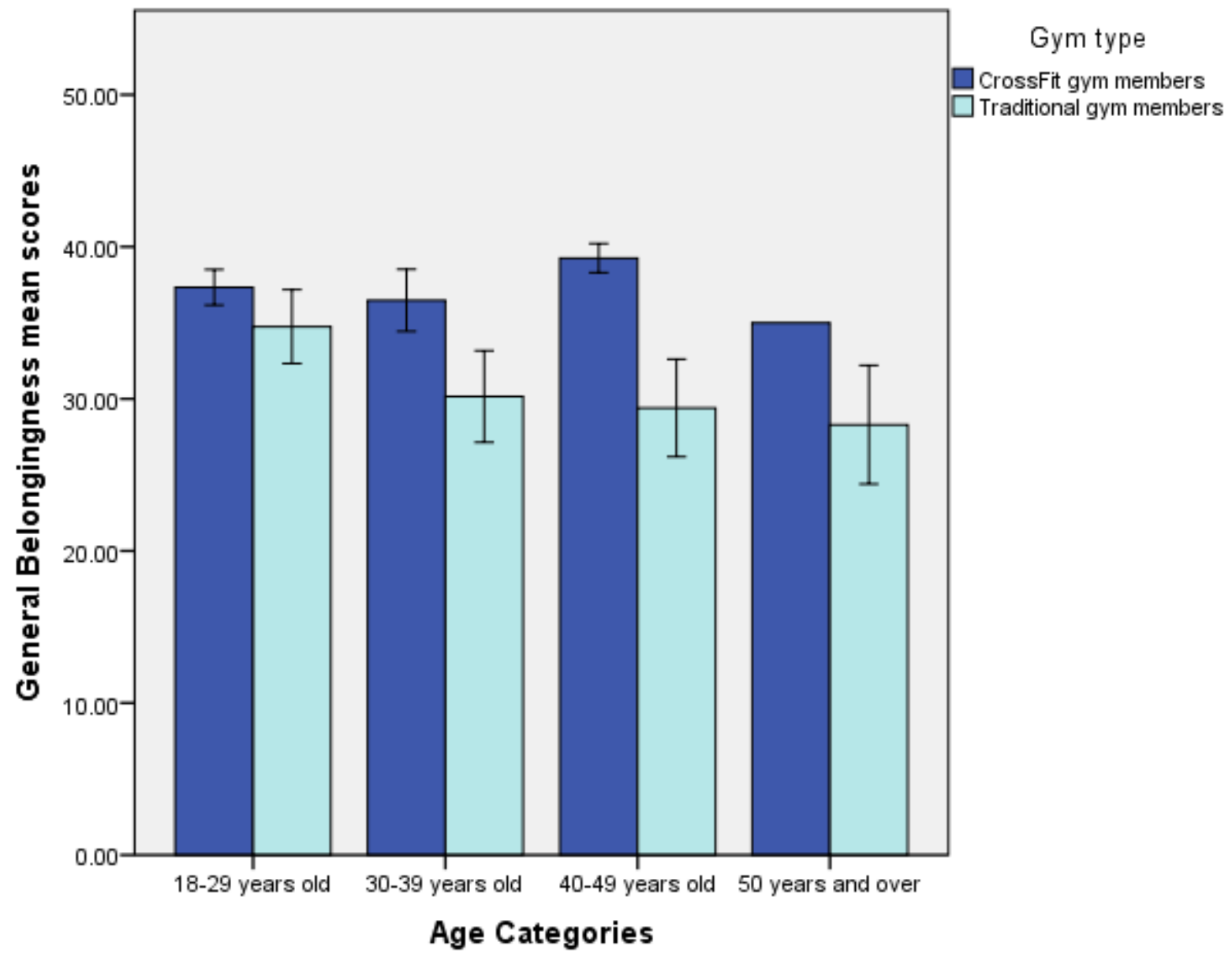

Error Bars: +/- $2 \mathrm{SE}$ 